JPE 11-4-17

\title{
Current Control Scheme of High Speed SRM Using Low Resolution Encoder
}

\author{
Huynh Khac Minh Khoi*, Jin-Woo Ahn**, and Dong-Hee Lee ${ }^{\dagger}$ \\ * Dept. of Electronics, TOSY Robotics JSC, Hanoi, Vietnam \\ $\dagger^{* * *}$ Dept. of Mechatronics Engineering., Kyungsung University, Busan, Korea
}

\begin{abstract}
This paper presents a balanced soft-chopping circuit and a modified PI controller for a high speed 4/2 Switched Reluctance Motor (SRM) with a 16 pulse per revolution encoder. The proposed balanced soft-chopping circuit can supply double the switching frequency in the fixed switching frequency of power devices to reduce current ripple. The modified PI controller uses maximum voltage, back-emf voltage and PI control modes to overcome the over-shoot current due to the time delay effect of current sensing. The maximum voltage mode can supply a fast excitation current with consideration of the hardware time delay. Then the back-emf voltage mode can suppress the current over-shoot with consideration of the feedback signal delay. Finally, the PI control mode can adjust the phase current to a desired value with a fast switching frequency due to the proposed balanced soft-chopping technology.
\end{abstract}

Key Words: 4/2 SRM, Current controller, High Speed, Low resolution encoder, Non-uniform air-gap

\section{INTRODUCTION}

High speed motor drive systems are very useful in practical applications such as blowers, compressors, pumps and spindle drives due to their compact size and system efficiency. Recently, the demands for high speed drives has increased a great deal due to the mechanical advantages of high speed systems [1]-[4]. A SRM has a simple structure and inherent mechanical strength without rotor windings or permanent magnets. These mechanical structures are suitable for harsh environments such as high temperature and high speed applications [5]-[9]. In many high speed drive systems, the number of poles is very important due to the electrical frequency and core losses from high frequencies. As a result, many high speed drives use a two-pole system to reduce the electrical frequency at the same speed. In addition, the number of phases is proportional to drive cost [4]-[8].

This paper presents a current control scheme for a high speed SRM using a low resolution encoder. Generally, high speed motors have a low electrical impedance due to their fast electrical dynamics when compared to conventional motors [8], [9]. For this reason, the current ripple in a high speed $\mathrm{SRM}$ is higher than it is in conventional motor systems in high speed operating conditions.

In order to reduce the current ripple, a high switching frequency is proper. However, the switching frequency is

\footnotetext{
Manuscript received Sep. 13, 2010; revised Apr. 20, 2011

Recommended for publication by Associate Editor Kyeong-Hwa Kim.

† Corresponding Author: leedh@ks.ac.kr

Tel: +82-51-663-4693, Fax: +82-51-663-4699, Kyungsung University

* Dept. of Electronics, TOSY ROBOTICS JSC, Vietnam

** Dept. of Mechatronics Eng., Kyungsung University, Korea
}

limited by the switching loss and the electrical characteristics of the power devices [9]-[11]. Furthermore, a high resolution optical encoder is not suitable in high speed motors due to the mechanical and electrical limitations of commercial encoders. Inaccurate rotor position from a low resolution encoder is not appropriate for the control of phase current without the overshoot phenomenon in the excitation period of a SRM due to the time delay of the hardware and the feedback signal of the phase current.

In order to reduce the current ripple in the prototype high speed SRM which is designed for an air-blower, a balanced soft-chopping circuit and a modified PI current control scheme with considerations for the current sensor delay and the motor speed is proposed. The prototype motor is designed for a high speed air-blower, and has a 30,000[rpm] rated speed with a 16 pulse per revolution encoder. Only the signals of a 2pulse encoder are activated during the phase current region. The signals can supply a simple switching pattern to the prototype motor. The balanced soft-chopping circuit uses an additional free-wheeling mode which uses non-activated power devices, so that the alternative switching can supply double the switching frequency of the power device. More of a fast switching frequency can suppress the current ripple in the same switching frequency of a power device.

The proposed modified PI current controller has 3-modes in the excitation region. These modes are the maximum voltage, back-emf and PI control modes. Each control mode is adapted to make a fast build-up of the phase current with consideration of the hardware time delay, and to suppress the over-shoot current from the feedback delay of the current 


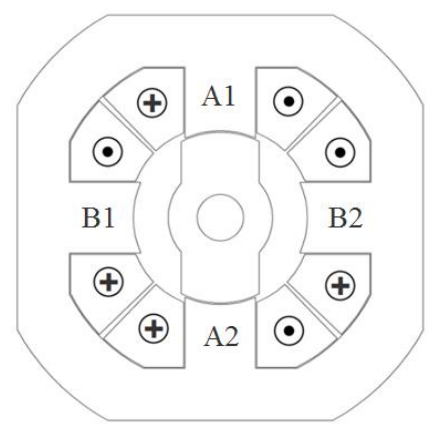

Fig. 1. The structure of a conventional 4/2 SRM.

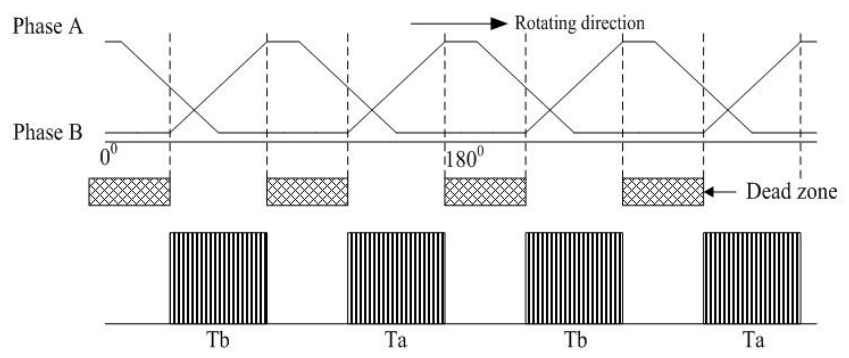

Fig. 2. Phase inductance and torque in a constant current.

sensing. The proposed current control scheme can build up a flat-top phase current without the over-shoot phenomenon with a low resolution encoder.

In order to verify the performance of the proposed control scheme for high speed drives, experimental test are implemented.

\section{PRototype 2-Phase 4/2 SRM}

The output torque of a SRM is produced by the alignment tendency of the stator and rotor poles. Also, the torque of each phase can be derived by the inductance and the phase current as follows [1]-[4]:

$$
T_{e}=\frac{1}{2} i^{2} \cdot \frac{d L(\theta, i)}{d \theta}
$$

where $L(\theta, i)$ is the inductance according to the rotor position and current.

Fig. 1 and 2 show a conventional 4/2 SRM and the torque characteristics according to the rotor position. As can be seen in Fig. 2, the output torque is produced during the variation region of the inductance, and the conventional 4/2 SRM has a torque dead-zone between two-phases. In the torque deadzone, the motor cannot produce a starting torque, so the motor cannot start in this region.

Fig. 3 and Table I show the proposed prototype high speed 4/2 SRM and its specifications. The SRM is designed for a high speed air-blower which has a 30,000[rpm] rated speed. Compared with a conventional SRM, the prototype motor has a wide rotor pole arc and a non-uniform air-gap to produce a wide, constant positive torque region. The non-uniform airgap is optimized to reduce torque ripple during the positive torque region. Since the motor is designed for an air-blower, the motor is operated in one direction.

Fig. 4 shows the analyzed inductance and torque profile of the designed motor. As shown in Fig. 4, the designed 2-phase

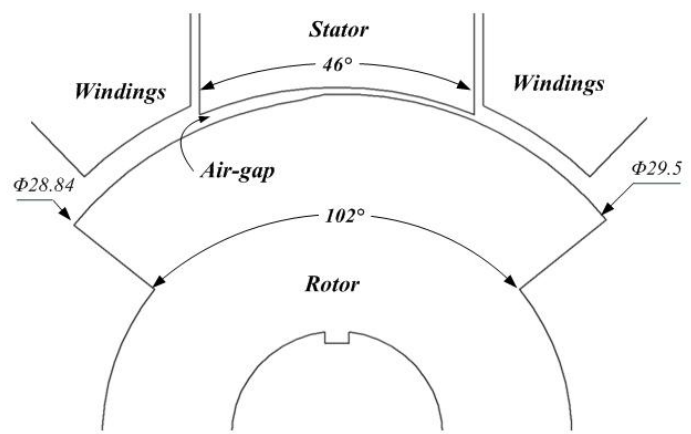

(a) Dimensions.

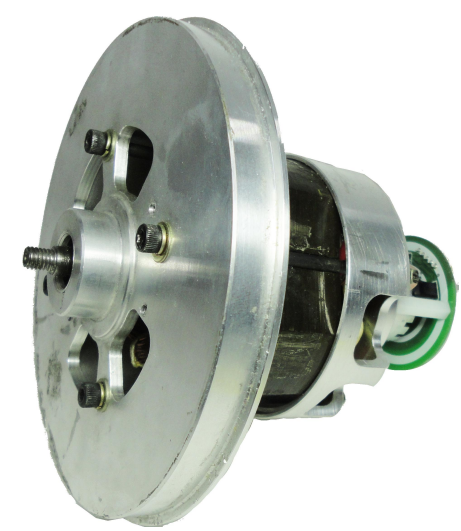

(b) Prototype SRM.

Fig. 3. Proto-type high speed 4/2 SRM.

motor has an asymmetric inductance characteristic which can produce wide positive and short negative torque regions. With consideration for the saturation effect, the proposed motor is optimized at 7[A] of phase current which is the rated current of the motor. As shown in Fig. 4, the inductance profile is very linear and the output torque is very constant under a light load. Under a heavy load, the saturation effect increases the torque ripple around the middle of the rotor pole.

In a high speed drive, a high resolution optical encoder can not be used due to the electrical dynamics and mechanical problem of encoders. In this paper, a low resolution 16 pulse optical encoder is used to detect the turn-on and turn-off positions of the motor. From the encoder, the switching pattern can be implemented, but the constant current control is very difficult due to the low resolution of the rotor position, the time delay of the hardware and the delay of the feed-back signals.

Furthermore, the impedance of the prototype SRM is very low. In order to reduce the current ripple, a high switching frequency is required. However, the switching frequency is limited by the switching loss and the power devices. In this paper, balanced soft-chopping control and advanced current control schemes are proposed to reduce the current ripple in high speed drives.

\section{Proposed Control Scheme}

\section{A. Balanced Soft-Chopping Control}

Fig. 5 shows the operating modes of the proposed balanced soft-chopping control. The conventional soft-chopping control uses excitation, free-wheeling and demagnetization modes. In 
TABLE I

SPECIFICATIONS OF THE PROTO-TYPE SRM

\begin{tabular}{l|ll}
\hline Parameters & Value & \\
\hline Rated output power & 600 & {$[\mathrm{~W}]$} \\
\hline Rated torque & 0.2 & {$[\mathrm{~N} . \mathrm{m}]$} \\
\hline Rated speed & 30,000 & {$[\mathrm{rpm}]$} \\
\hline Rated current & 7 & {$[\mathrm{~A}]$} \\
\hline Number of stator poles & 4 & \\
\hline Number of rotor poles & 2 & \\
\hline Bore diameter & 30 & {$[\mathrm{~mm}]$} \\
\hline Outer stator diameter & 80 & {$[\mathrm{~mm}]$} \\
\hline Stack length & 30 & {$[\mathrm{~mm}]$} \\
\hline Minimum air-gap & 0.25 & {$[\mathrm{~mm}]$} \\
\hline Stator pole arc & 46 & {$[\mathrm{Deg}]$.} \\
\hline Rotor pole arc & 102 & {$[\mathrm{Deg}]$.} \\
\hline Number of turns & 150 & {$[\mathrm{turn}]$} \\
\hline $\mathrm{R}_{\mathrm{ph}}$ & 0.5 & {$[\mathrm{Ohm}]$} \\
\hline $\mathrm{L}_{\mathrm{u}}$ (unalignedinductance) & 2 & {$[\mathrm{mH}]$} \\
\hline
\end{tabular}

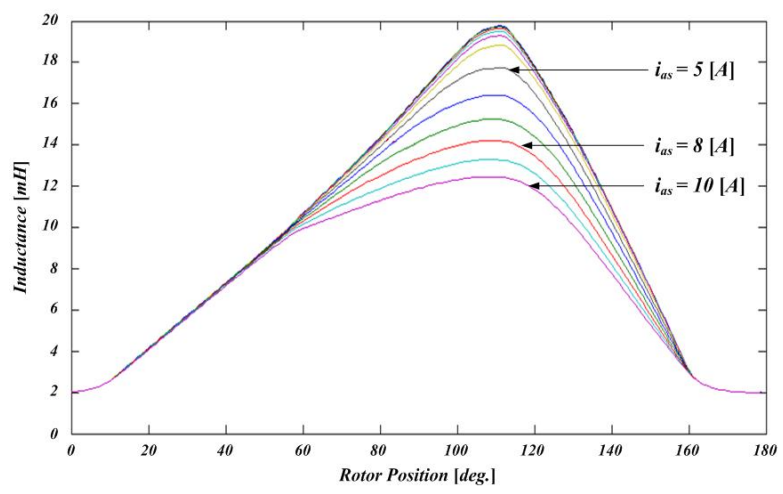

(a) Inductance profile.

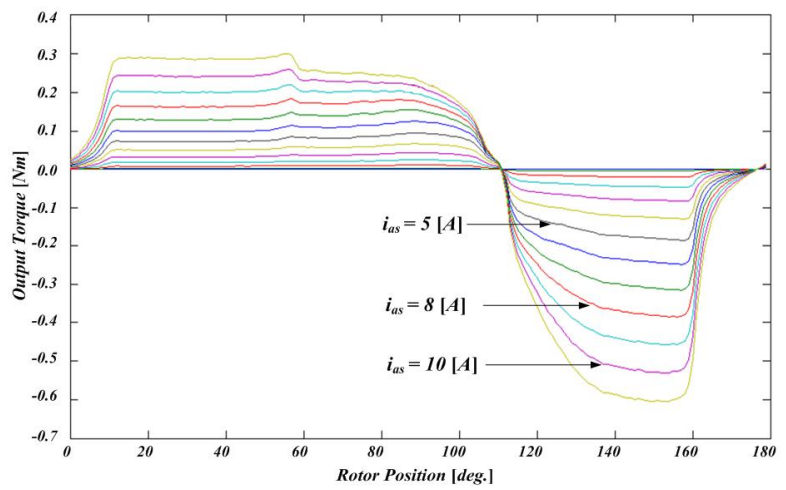

(b) Torque profile.

Fig. 4. Inductance and torque characteristics of the proposed 4/2 SRM.

a high speed drive, the phase current ripple is dependent on the switching frequency. However, the switching frequency is limited by the switching loss and power devices. In order to reduce the current ripple with the same switching frequency in any power devices, balanced soft-chopping is very useful. The balanced soft-chopping control has two free-wheeling modes as can be seen in Fig. 5(c) and Fig. 5(d). These two freewheeling modes are alternatively used in the operating region.

Fig. 6 shows the basic principle of the balanced softchopping control scheme. Compared with a conventional control scheme, the balanced soft-chopping control scheme uses an excitation mode and free-wheeling mode- 1 , followed by an excitation mode and free-wheeling mode-2. In this alterna-

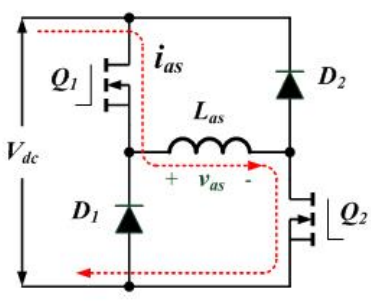

(a) Excitation mode(M1).

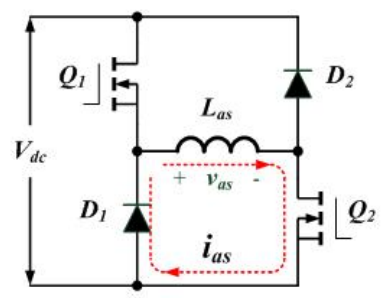

(c) Free-wheeling mode-1(M3). (b) Demagnetization mode(M2).

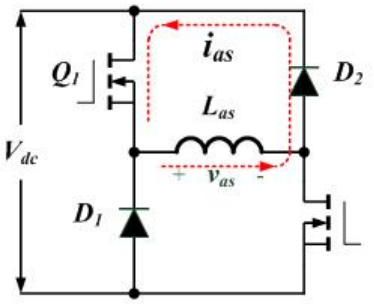

(d) Free-wheeling mode-2(M4).

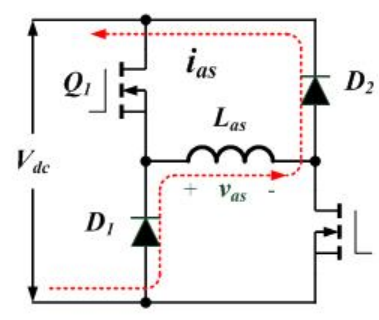

Fig. 5. Operating modes of the balanced soft chopping.

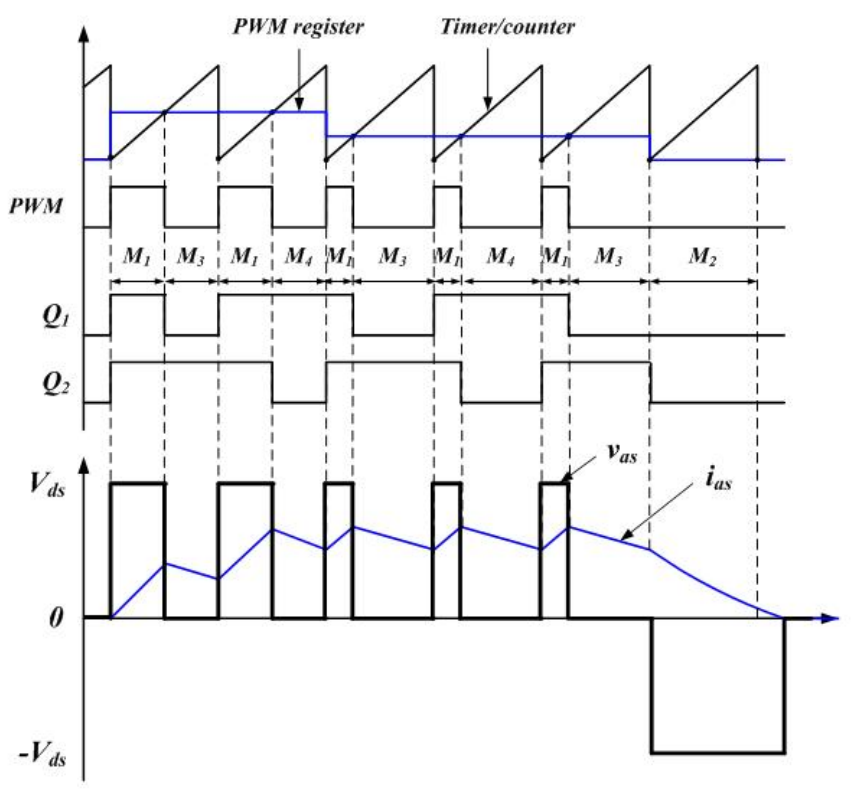

Fig. 6. PWM and switching signals for balanced soft-chopping.

tive switching technology, the current switching frequency is double the switching frequency of each of the power devices shown in Fig. 6.

From this switching technology, the switching stress can be equally distributed to the each of the power devices with a fast switching frequency. Fig. 7 shows a practical implementation of the proposed balanced soft-chopping circuits.

\section{B. Current Control Scheme}

In a high speed drive, the electrical frequency is much higher than the mechanical rotating speed. The prototype $4 / 2$ SRM has a $30,000[\mathrm{rpm}]$ rated speed and the mechanical frequency is $500[\mathrm{~Hz}]$. Also, the electrical frequency of a phase is $2[\mathrm{kHz}]$ and the positive torque region is $500[\mu \mathrm{s}]$ ideally. From the fast electrical frequency, the proparagation delay of 


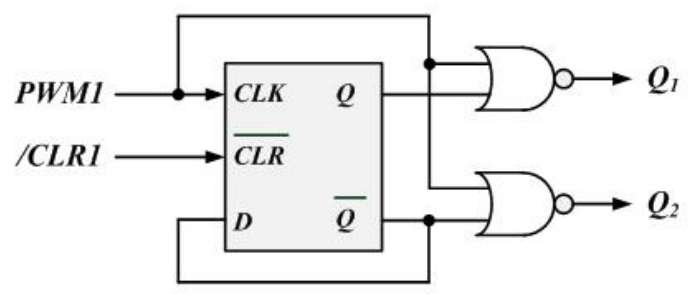

Fig. 7. Practical implementation of the balanced soft-chopping.

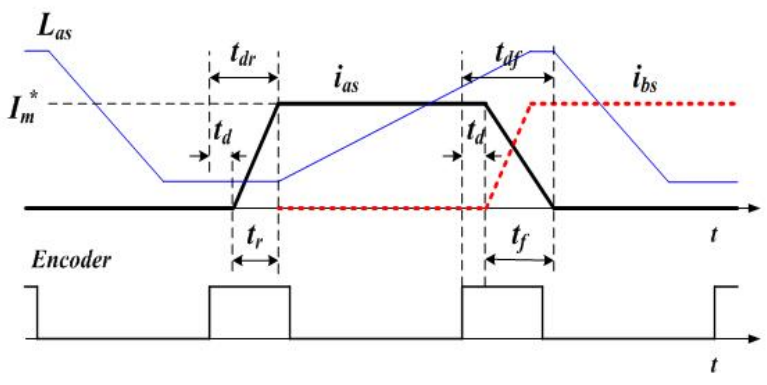

Fig. 8. Phase current and encoder signal.

the sensor is very important.

Fig. 8 shows the signal of a practical low resolution encoder and the phase current. From the encoder signal, the gate signal has a time delay $t_{d}$ due to the gate circuit dynamics and the encoder signal interrupt latency which is almost constant in the given hardware. Also, the rising time $t_{r}$ is dependent on the desired current $I_{m}^{*}$, the phase voltage and the impedances such as the inductance and the resistance. At this position, the inductance of the motor is in the minimum region.

If the stator winding resistance is ignored, the rising and falling time delays can be derived as follows:

$$
\begin{gathered}
t_{r}=\frac{L_{\min } \cdot I_{m}^{*}}{v_{a s}} \\
t_{f}=\frac{L_{a s}\left(\theta_{o f f}, i_{a s}\right) \cdot I_{m}^{*}}{V_{d c}} \\
t_{d r}=t_{d}+t_{r} \\
t_{d f}=t_{d}+t_{f} .
\end{gathered}
$$

In this paper, the turn-on and turn-off times are determined based on considerations of the signal delay and reference current value. Nevertheless in the consideration of the time delay, the excitation current may have a high over-shoot due to the fast excitation time in the high speed region. In order to reduce the current over-shoot, a 3 mode excitation current controller is proposed.

Fig. 9 shows the proposed current controller and the time schedule of the operating modes. The 3-modes are the maximum voltage, back-emf voltage and PI control modes. For a fast excitation, the maximum voltage of the converter is supplied during the calculated rising time from the turn-on position. In the asymmetric converter, the maximum voltage is the dc-link voltage, and the output PWM has a 100[\%] duty ratio. The time of the maximum voltage mode is derived based on the rising time which is calculated in (2). Then, the backemf voltage is applied during the fixed time $t_{m 2}$. In this region, the actual current reaches the desired current. However, the

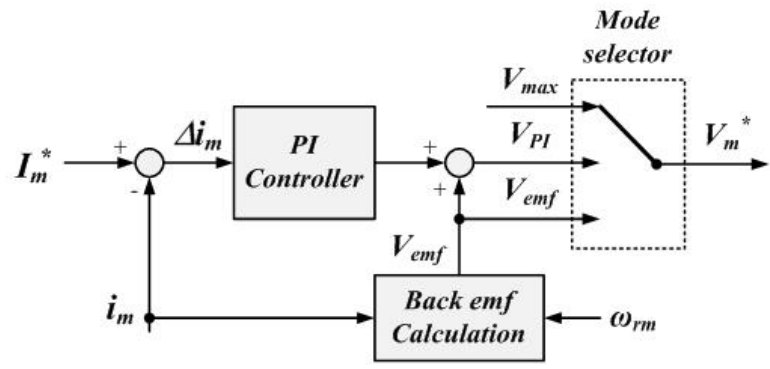

(a) Proposed current controller.

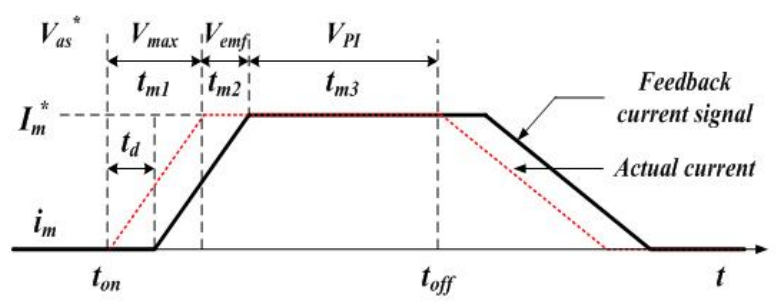

(b) Time schedule.

Fig. 9. Proposed current controller.

feedback current signal is still less than the desired current due to the hardware delay. During the back-emf voltage mode, the calculated back-emf voltage is supplied to the phase winding, and the current controller is waiting for the feedback current signal.

The phase voltage is lower than the dc-link voltage, and the phase current can keep a constant value in this mode. After the back-emf voltage mode, the PI controller regulates the current control voltage. In this paper, the back-emf voltage mode is set to $100[\mu \mathrm{s}]$ with consideration of the signal delay

The calculation of the back-emf can be executed simply due to the non-saturated linear characteristics of the inductance profile shown in Fig. 4(a). Also, each of the mode voltages can be derived as follows:

$$
\begin{gathered}
V_{\max }=V_{d c} \\
V_{e m f}=i_{m} \frac{d L(\theta, i)}{d \theta} \cdot \omega_{r m} \\
V_{P I}=K_{p} \cdot \Delta i_{m}+K_{i} \int \Delta i_{m} \cdot d t+V_{e m f}
\end{gathered}
$$

where, $L(\theta, i)$ is the non-linear inductance of the prototype SRM. In the calculation of the back-emf voltage $V_{e m f}, \frac{d L(\theta, i)}{d \theta}$ is the inductance slope according to the rotor position and current. This is almost the same and constant due to the nonsaturated linear characteristics in the unaligned position. As shown in Fig. 8, each of the phase windings are turned on in the unaligned position where the inductance has its minimum value and linear characteristics. Therefore, the constant inductance slope and the motor speed are multiplied by the phase current without a complex look-up table.

\section{EXPERIMENTAL RESUlTS}

In order to verify the proposed control scheme, experimental tests are implemented. A DSC (Digital Signal Controller) with an embedded 12bit ADC and the PWM function is used for the design of the controller. A low resolution encoder signal 


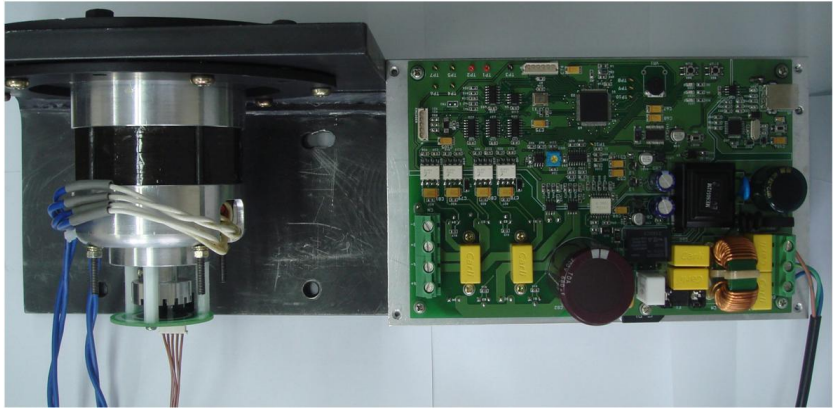

Fig. 10. Experimental configuration.

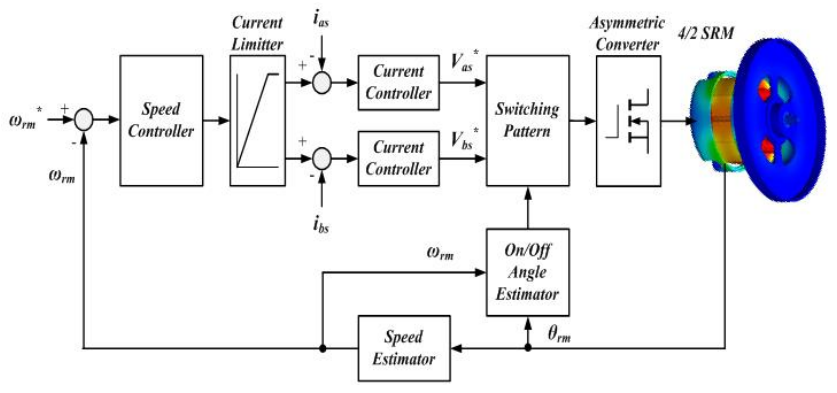

Fig. 11. Block diagram of the proposed drive system.

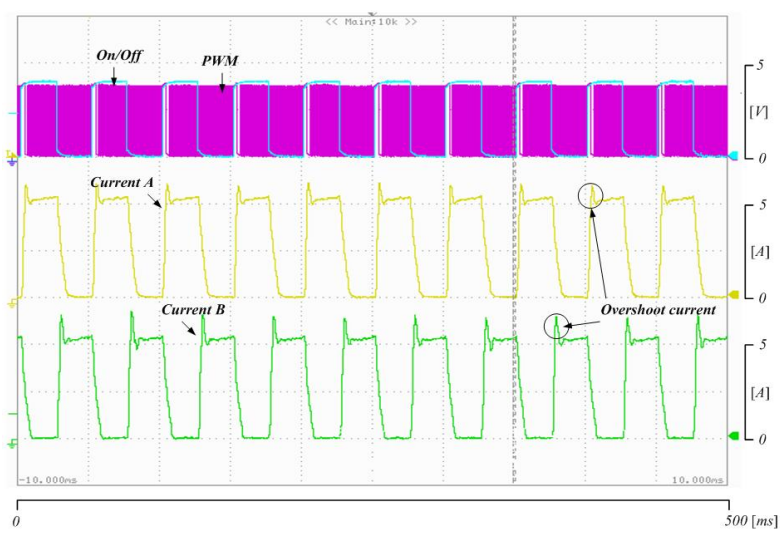

(a) Current and PWM signals.

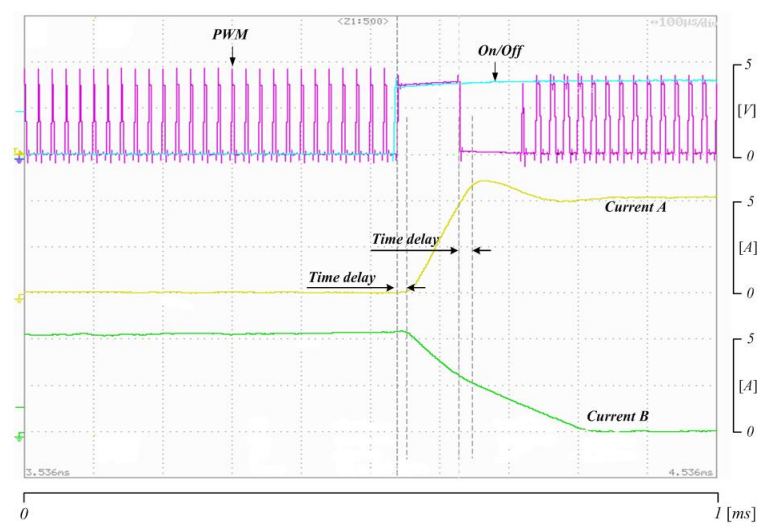

(b) Extended of (a).

Fig. 12. Current over-shoot from the time delay effect in a conventional PI controller.

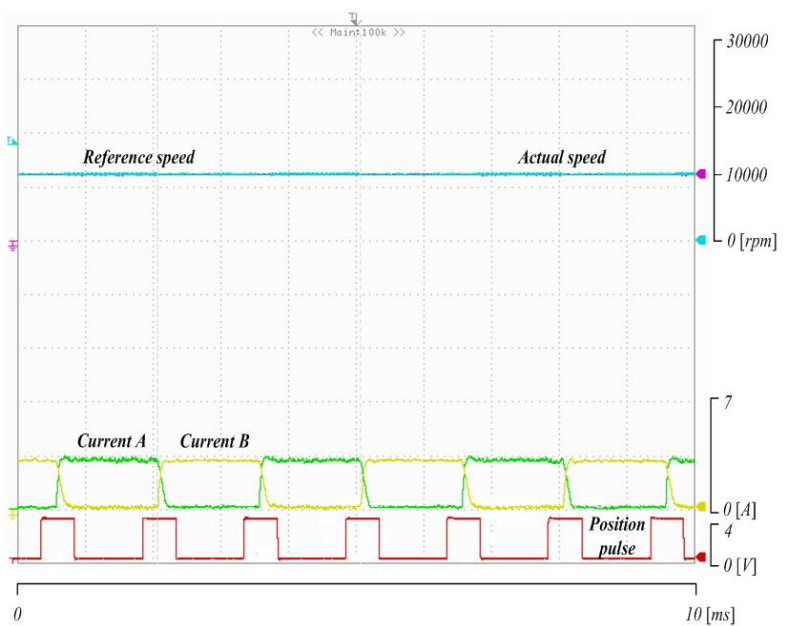

(a) At $10,000[\mathrm{rpm}]$.

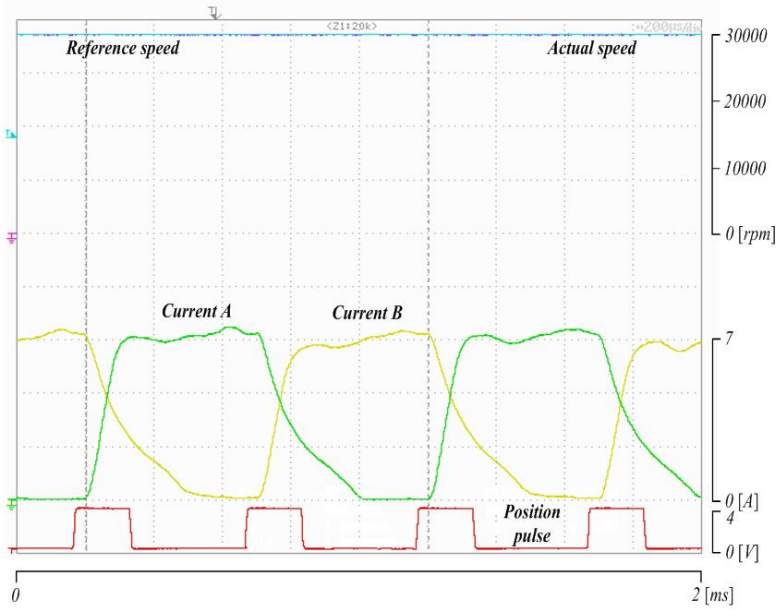

(b) At 30,000[rpm].

Fig. 13. Experimental results of the proposed control scheme.

is input to the external interrupt of the DSC. At each rising and falling edge of the encoder signal, the DSC can check the encoder signal with the short interrupt latency time of the DSC.

Fig. 10 shows the experimental configurations. A 2-phase asymmetric converter and a DSC (TMS320F2811) are used for the motor control. The current of the motor is detected by a mounted chip-type current sensor (ACS712) and the embedded $12 \mathrm{bit}$ ADC of the DSC. The rotor position sensor has 16 pulses per revolution with an ultra fast opto-interrupter and the signal is connected to the QEP module and the external interrupt of the DSC. The controller can count 64 pulse per revolution with the phase detecting signal. The converter consists of a FET which has a $600[\mathrm{~V}], 25[\mathrm{~A}]$ power rating. Also, the switching frequency for each of the power devices is $50[\mathrm{kHz}]$.

Fig. 11 shows a speed control block diagram of the prototype high speed SRM. Each of the phase current controllers are designed for the proposed current control scheme. The on/off angle estimator calculates the turn-on and turn-off times from the encoder pulse.

Fig. 12 shows the experimental results for a conventional PI current controller. As shown in Fig. 12, the phase current has a high over-shoot due to the time delay effect. The PI 


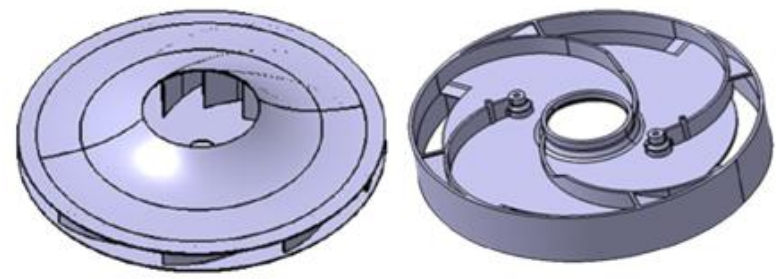

(a) Adopted impeller structure.

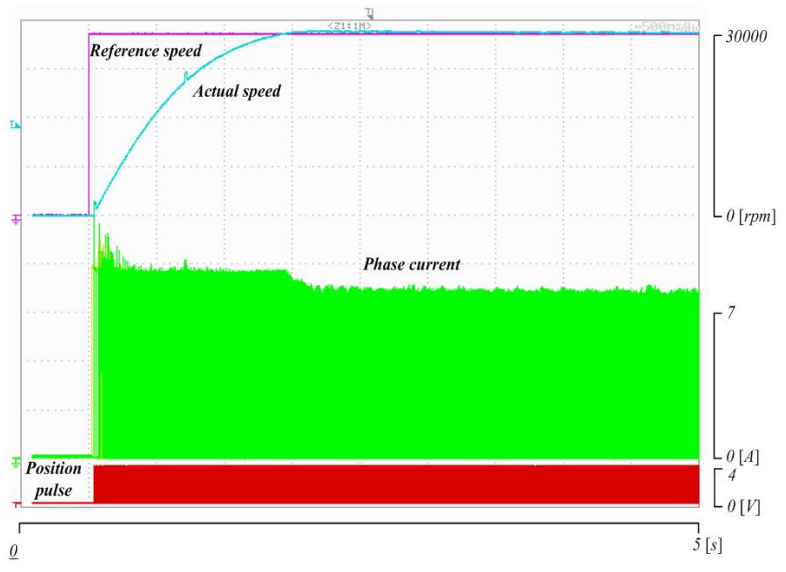

(b) Drive characteristics of an air-blower.

Fig. 14. Experimental result of a practical air-blower.

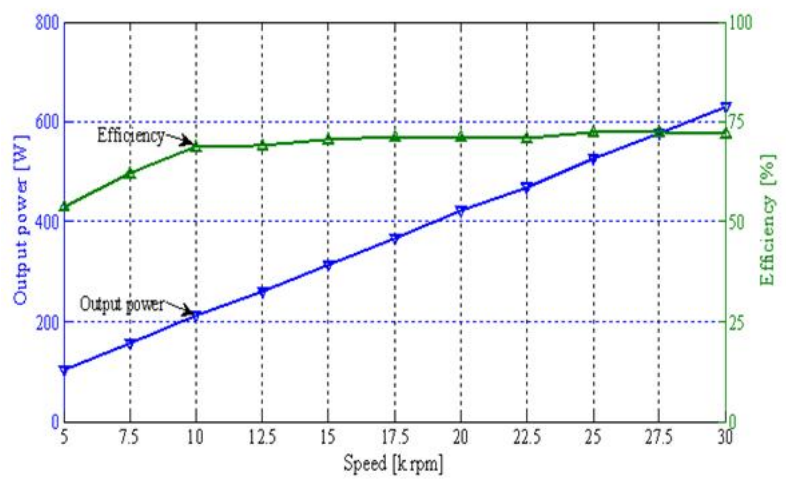

Fig. 15. Efficiency and output power of air-blower.

current controller reads the delayed signal and not the actual value of the current because of the time delay of the feedback current signal. During this time interval, the practical current is increased over the desired current.

Fig. 13 shows the experimental results for the proposed control scheme at $10,000[\mathrm{rpm}]$ and 30,000[rpm], respectively. As shown in Fig. 13, the phase currents are controlled without any over-shoot. The turn-on and turn-off times are determined with consideration of the hardware time-delay, and the excitation current is controlled by the proposed current controller.

Fig. 14 shows the adopted impeller and practical air-blower test results. A commercial impeller for a high speed air-blower is used for the experiments. The practical load of the motor is exponentially increased according to the motor speed. Also, the maximum load is suppressed at 30,000 [rpm]. As shown in Fig. 14, the proposed control scheme keeps the reference speed well, and it reaches the target speed within $1.5[\mathrm{~s}]$ without any oscillations.
Fig. 15 shows the measured output torque, power and efficiency of the motor. The output torque and power are satisfied with the desired value. The maximum efficiency of the system is $72.2[\%]$, which is much higher than the efficiency of an universal motor.

\section{CONCLUSIONS}

This paper presents a balanced soft-chopping and a modified PI controller for a high speed 4/2 SRM. The prototype SRM has a non-constant air-gap structure for a wide positive torque without a torque dead-zone. Also, the position sensor generates 16 pulses per revolution. The proposed balanced soft-chopping circuit can supply double the switching frequency with a fixed switching frequency for power devices to reduce current ripple. The modified PI controller uses fast excitation, backemf voltage and PI control modes to reduce the over-shoot current which is from the time delay effect of the current sensing. The successively supplied phase voltage can build up the excitation current quickly without a current over-shoot.

The proposed control scheme is tested with a practical airblower system using the prototype high speed 4/2 SRM. From the experiments, it can be seen that the proposed control scheme can suppress the over-shoot current, and the actual speed can keep the reference speed well.

\section{ACKNOWLEDGMENT}

This work was supported by the Energy Resource R\&D Program (2009T100100654) under the Ministry of Knowledge Economy, Republic of Korea.

\section{REFERENCES}

[1] R. Krishnan, Switched reluctance motors drives: Modeling, simulation, analysis, design, and application, CRC Press, 2001

[2] N. Bianchi, S. Bolognani, and F. Luise, "High speed drive using a slotless PM motor," IEEE Trans. Power Electron., Vol. 21, No.4, pp. 1083-1090, Jul. 2006.

[3] M. J. Turner, P. Y. P. Wung, and R. S. Wallace, "Comparing European 132 frame switched reluctance and induction motor drives," in Proc. IECON, Vol. 2, pp. 403- 408, 1997.

[4] T. Higuchi, J. O. Fiedler, and R. W. De Doncker, "On the design of a single-phase switched reluctance motor," in Proc. IEMDC, Vol. 1, pp. 561-567, 2003.

[5] S. Kozuka, N. Tanabe, J. Asama, and A. Chiba, "Basic characteristics of 150,000r/min switched reluctance motor drive," in Proc. Power and Energy Society General Meeting, pp. 1-4, 2008.

[6] H. Kuss, T. Wichert, and B. Szvmanski, "Design of a high speed Switched Reluctance Motor for spindle drive," in Proc. CPE, pp.1-5, 2007.

[7] K. Kajiwara, Y.-J. Kim, and H. Dohmeki, "Analysis of the maximizing start torque of Switched Reluctance Motor for super high speed drive," in Proc. ICEMS, pp.1428-1432, 2007.

[8] T. Genda and H. Dohmeki, "Characteristics of 4/2 Switched Reluctance Motor for a high speed drive by the excitation angle," in Proc. ICEMS, pp. 1-6, Nov. 2009.

[9] I. R. Kartono, K. Kajiwara, and H. Dohmeki, "Dynamic simulation of maximizing the starting torque for super-high-speed drive of a $4 / 2$ Switched Reluctance Motor," in Proc. ICEMS, pp. 1-6, Sep. 2008.

[10] J. W. Ahn, T. H. Kim, and D. H. Lee, "Performances of SRM for LSEV," Journal of Power Electronics, Vol. 5, No. 1, pp. 45-54, Jan. 2005.

[11] K. Ohyama, M. Naguib, F. Nashed, K. Aso, H. Fujii, and H. Uehara, "Design using finite element analysis of a switched reluctance motor for electric vehicle," Journal of Power Electronics, Vol. 6, No. 2, pp. 163-171, Apr. 2006. 


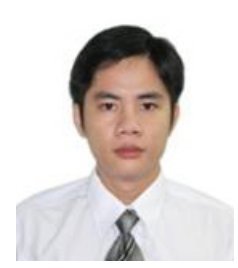

Huynh Khac Minh Khoi was born in Tra Vinh, Vietnam, in 1984. He received his B.S. in Electrical Engineering from the University of Technology, Ho Chi Minh City, Vietnam, in 2007 and his M.S. in Electrical Engineering from Kyungsung University, Busan, Korea, in 2010. Since 2010, he has been with the Electronics Department, TOSY Robotics JSC., Hanoi, Vietnam where he is currently a R\&D Engineer. His current research interests include the design and advanced control of electrical machines, and power electronics.

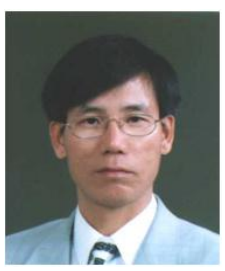

Jin-Woo Ahn was born in Busan, Korea, in 1958. He received his B.S., M.S. and Ph.D. in Electrical Engineering from Pusan National University, Busan, Korea, in 1984, 1986, and 1992, respectively. He has been with Kyungsung University, Busan, Korea, as a Professor in the Department of Mechatronics Engineering since 1992. He was a Visiting Researcher in the Speed Lab at Glasgow University, U.K., a Visiting Professor in the Dept. of ECE and WEMPEC at the University of Wisconsin-Madison, USA, and a Visiting Professor in the Dept. of ECE at Virginia Tech, from 2006 to 2007. He was the Director of the Advance Electric Machinery and Power Electronics Center, from 2004 to 2008. He has also been the Director of the Smart Mechatronics Advanced Research and Training Center since August 2008 and the Senior Easy Life Regional Innovation System since July 2008, which are authorized by the Ministry of Knowledge Economy, Korea. He is the author of five books including SRM, the author of more than 120 papers and has several patents. His current research interests include advanced motor drive systems and electric vehicle drives. Dr. Ahn has received several awards including a Best Paper Award
(2002), an Academic Achievement Award (2003) and a Park Min-Ho Special Award (2009) from the Korean Institute of Electrical Engineers. He has also received a Best Paper Award (2003) from the Korean Federation of Science and Technology, and an Academic Achievement Award (2003), a Technology Achievement Award (2004) and a Best Paper Award (2007) from Korean Institute of Power Electronics, respectively. He was also received a Best Research Professor award (2008), a Best Industrial Cooperation Award (2009) and a Merit Award (in both 2009 and 2010) from Kyungsung University. He is a Fellow Member of the Korean Institute of Electrical Engineers, a member of the Korean Institute of Power Electronics and a Senior Member of the IEEE. He is Chairman of the Academic Committee, KIEE and Vice president of the Korea Regional Innovation System Association. He is now serving as an Editor-in-Chief of JEESEM (Journal of Emerging Energy Systems and Electric Machines) which is a joint publication of the Korean Institute Electrical Engineers (KIEE), the Institute of Electrical Engineering of Japan (IEEJ), the China Electrotechnical Society (CES) and the Industry Application Society (IAS)

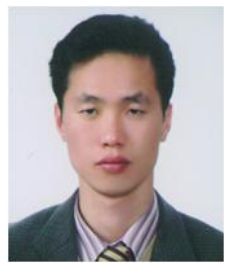

Dong-Hee Lee was born on November 11, 1970 and received his B.S., M.S. and Ph.D. in Electrical Engineering from Pusan National University, Pusan, Korea, in 1996, 1998 and 2001, respectively. He worked as a Senior Researcher in the Servo R\&D Team at OTIS-LG from 2002 to 2005. He has been with Kyungsung University, Pusan, Korea, as an Assistant Professor in the Department of Mechatronics Engineering since 2005. His current research interests include Power Electronics and motor control systems. 